\title{
Classification and identification of bunching onion (Allium fistulosum) varieties based on SSR markers
}

\author{
Hikaru Tsukazaki*1), Masanori Honjo ${ }^{2,3)}$, Ken-ichiro Yamashita1), Takayoshi Ohara'), Akio Kojima1), \\ Ryo Ohsawa ${ }^{2)}$ and Tadayuki Wako') \\ 1) National Institute of Vegetable and Tea Science (NIVTS), 360 Ano-Kusawa, Tsu, Mie 514-2392, Japan \\ 2) Graduate School of Life and Environmental Sciences, University of Tsukuba, 1-1-1 Tennoudai, Tsukuba, Ibaraki 305-8572, Japan \\ 3) Present address: National Agricultural Research Center for Tohoku Region (NARCT), 4 Akahira, Shimo-kuriyagawa, Morioka, Iwate \\ 020-0198, Japan
}

\begin{abstract}
We investigated the correspondence between classifications based on simple sequence repeat (SSR) markers and on morphological traits for 30 bunching onion (Allium fistulosum L.) varieties. We also examined applicability of an assignment test for variety identification in bunching onion. Cluster analysis based on the allele frequency data at 29 SSR loci classified most of the varieties except for 'Iwatsuki-2' into the predicted variety groups, 'Kaga', 'Senju' or 'Kujo', which were categorized based on morphological traits. Although 'Iwatsuki-2' has been regarded as a member of 'Kaga' group, molecular data suggested the variety belonging to 'Kujo' rather than 'Kaga'. In the assignment test at the individual level, $89.1 \%$ of the individuals were assigned to their original variety. When the assignment was conducted based on groups each consisting of four individuals, the percentage of correct assignments was considerably improved (99.3\%). These results suggested that the assignment test approach will be useful for variety identification in allogamous bunching onions, which have large within-variety genetic diversity. On the other hand, it was also suggested that sampling of true source varieties will be fundamental to avoid misjudgment.
\end{abstract}

Key Words: Allium fistulosum, bunching onion, classification, SSR markers, variety identification.

\section{Introduction}

Bunching onion (A. fistulosum L.) is considered to have originated in northwestern China and is mainly cultivated in East Asian countries, in particular in Japan, China and Korea (Kumazawa and Katsumata 1965, Ford-Lloyd and Armstrong 1993). In Japan, bunching onion has a high annual output among fruit and vegetables, following tomato, strawberry, and cucumber (MAFF 2008). Many local varieties are adapted to various climatic conditions, and are classified into four groups_-'Kaga', 'Senju', 'Kujo' and 'Yagura-Negi' - according to morphological and ecological traits (Inden and Asahira 1990).

The main breeding objectives for bunching onion are disease resistance, high yield, late bolting, high consumer qualities (e.g., low pungency, high sugar content) and suitability for mechanized farming (e.g., vigorous seedling growth). As for the seedling growth, we reported that $F_{1}$ between the Senju and Kujo groups showed remarkable heterosis (Ohara et al. 2004). Also, the genetic distances based on AFLPs showed significant correlation with the degree of heterosis over the mid-parent for each seedling trait in bunching onion

Communicated by T. Hayashi

Received October 20, 2009. Accepted May 11, 2010.

*Corresponding author (e-mail: tsuka@affrc.go.jp)
(Ohara et al. 2005a). To exploit the genetic potential of heterosis, it is important to clarify the genetic relationships among varieties and to explore heterotic groups on the basis of variety classification using molecular markers. Haishima et al. (1993) reported the first phylogenetic analysis of bunching onion. They reported that groups 'Kaga' and 'Senju' were categorized separately based on a cluster analysis of genetic distance data at eight isozyme loci among 13 bunching onion varieties. Previously, we attempted a classification of 11 inbred lines with cluster analysis based on 128 AFLPs (Ohara et al. 2005a). This classification was in accordance with the traditional classification using morphological and ecological traits. However, these markers are less polymorphic and do not reflect genetic structure (isozyme) or are less discriminative due to dominant inheritance (AFLP).

On the other hand, SSRs are ideal DNA markers due to their simplicity, reproducibility and codominant inheritance. In the genus Allium, Fischer and Bachmann (2000) first reported SSR markers from bulb onion (A. cepa L. Common onion group) and used these for a phylogenetic analysis of Allium species. From large-scale sequencing of bulb onion expressed sequence tags (ESTs), hundreds of EST-derived SSR markers have also been developed (Kuhl et al. 2004, Martin et al. 2005). In our previous study, we isolated thousands of SSRs from a genomic library of bunching onion (Wako et al. 2002, Song et al. 2004, Tsukazaki et al. 2007), 
and some of these were used to construct a linkage map of bunching onion (Ohara et al. 2005b, Tsukazaki et al. 2008). The SSR markers, which have been mapped on a linkage map, will be useful for assessing the genetic relationships of bunching onion varieties, although no attempt has been made to use them for the variety classification of bunching onion.

Moreover, variety identification based on molecular markers also becomes important from the point of view of protection of breeder's right. The assignment test, which assigns each individual to a reference variety in which its multilocus genotype is most likely to occur (reviewed by Manel et al. 2005), may allow us to identify the variety in allogamous plant species (Kubik et al. 2001, Tommasini et al. 2003).

The purpose of this study was (1) comparing classifications based on allele frequency data of SSR loci and on morphological traits, and (2) verifying possibility of variety identification in bunching onion which contains high degree of within-variety diversity. In this paper, we report on the first study that attempted variety classification using SSR markers.

\section{Materials and Methods}

\section{Plant materials}

A total of 30 open-pollinated (OP) varieties of bunching onion were used in this study (Table 1). These varieties include not only representatives of three major variety groups, 'Kaga', 'Senju' and 'Kujo', but also another group 'Okunegi' and one Chinese variety. These were selected as standard varieties based on principal component analysis (PCA) of nine morphological traits in our previous study (Wako et al. 2009, Fig. 1). The $1^{\text {st }} \mathrm{PC}$ (contributing $47.4 \%$ to the varia- tion) was mainly associated with length-related traits, and the $2^{\text {nd }} P C$ (contributing $20.0 \%$ ) was associated with widthrelated traits.

Two species related to bunching onion were also included: an accession of $A$. altaicum Pall. COL/KAZ/1997/ NIVOT/86 and an open-pollination variety of bulb onion (A. cepa. L.) 'Kaizuka-Wase-Ki'. These species and bunching onion belong in section Cepa within Allium, and A. altaicum is considered a progenitor of $A$. fistulosum (Friesen et al. 1999).

Total DNA was extracted from young leaves of each plant (24 individuals/variety) according to Song et al. (2004).

\section{SSR markers and PCR}

Thirty-three SSR markers were used for genotyping individuals (Table 2). SSR markers were selected to be evenly distributed across each linkage group of the bunching onion map (1-4 loci per linkage group) (Tsukazaki et al. 2008). Of these, ACM096, ACE010 and ACE044 are bulb onion ESTderived SSR markers (Kuhl et al. 2004, Tsukazaki et al. 2008), and AMS14 is a bulb onion genomic SSR marker developed by Fischer and Bachmann (2000). All markers, except for AFS103, have been located on the bunching onion linkage map (Tsukazaki et al. 2008).

PCR amplification was performed according to Tsukazaki et al. (2008); however, forward primers were fluorescentlabeled with 6-FAM, NED, PET or VIC dyes (Applied Biosystems, CA, USA) prior to use. PCR products were loaded onto a capillary DNA sequencer (ABI3730; Applied Biosystems), and analyzed using GeneMapper ver. 3.0 software (Applied Biosystems). Some PCR fragments were purified and sequenced according to Tsukazaki et al. (2008).

Table 1. List of 30 bunching onion varieties and two related species used in this study

\begin{tabular}{|c|c|c|c|c|c|c|c|}
\hline $\begin{array}{l}\text { Variery } \\
\text { no. }\end{array}$ & Group (subgroup) & $\begin{array}{l}\text { Accession } \\
\text { No. }\end{array}$ & Variety name & No. & $\begin{array}{l}\text { Group (subgroup)/ } \\
\text { species }\end{array}$ & $\begin{array}{l}\text { Accession } \\
\text { No. }\end{array}$ & Variety name \\
\hline 1 & \multirow[t]{4}{*}{ Kaga (Shimonita) } & JP127028 & Shimonita & 17 & \multirow[t]{3}{*}{ Senju (Aigara) } & JP127027 & Nishida \\
\hline 2 & & JP133859 & Aji-Ipponfuto & 18 & & JP133854 & Kiyotaki \\
\hline 3 & & JP133921 & Raitei-Shimonita & 19 & & JP25470 & Toyokawafuto \\
\hline 4 & & - & Miyanegi & 20 & \multirow[t]{3}{*}{ Kujo (Koshizu) } & JP127042 & Koshizu-Aigarakei \\
\hline 5 & \multirow[t]{3}{*}{ Kaga (Kaga) } & JP133844 & Amarume-Ipponfuto & 21 & & JP25471 & Koshizu-Nebuka \\
\hline 6 & & JP133872 & Matsumoto-Nebukafuto & 22 & & JP25474 & Koshizu \\
\hline 7 & & JP25431 & Gengo & 23 & \multirow[t]{3}{*}{ Kujo (Kujofuto) } & JP133890 & Ajiyoshi \\
\hline 8 & \multirow[t]{3}{*}{ Kaga (Iwatsuki) } & JP133914 & Iwatsuki-1 & 24 & & JP133928 & Kujofuto-1 \\
\hline 9 & & JP127040 & Jionji & 25 & & JP133847 & Kujofuto-2 \\
\hline 10 & & JP133870 & Iwatsuki-2 & 26 & \multirow[t]{3}{*}{ Kujo (Kujohoso) } & JP133886 & Wakamidori \\
\hline 11 & \multirow[t]{3}{*}{ Senju (Kurogara) } & JP133875 & Yoshikura & 27 & & JP133852 & Asagikei-Kujo-1 \\
\hline 12 & & JP138766 & Kachinanori & 28 & & JP133916 & Asagikei-Kujo-2 \\
\hline 13 & & JP133888 & Choho & 29 & Okunegi & JP133877 & Motoharu-Bansei \\
\hline $\begin{array}{l}14 \\
15\end{array}$ & \multirow[t]{2}{*}{ Senju (Aiguro) } & $\begin{array}{l}\text { JP133891 } \\
\text { IP133906 }\end{array}$ & Kanehiko & 30 & China & JP138782 & Shokyu \\
\hline $\begin{array}{l}15 \\
16\end{array}$ & & $\begin{array}{l}\text { JP133906 } \\
\text { JP133905 }\end{array}$ & $\begin{array}{l}\text { 1 okyo-Fuyuguro-Ipponfuto } \\
\text { Omiyakuro }\end{array}$ & $\begin{array}{l}31 \\
32\end{array}$ & $\begin{array}{l}\text { Allium altaicum } \\
\text { A. cepa }\end{array}$ & $\begin{array}{l}\text { JP138870 } \\
\text { JP25385 }\end{array}$ & $\begin{array}{l}\text { COL/KAZ/1997/NIVOT/86 } \\
\text { Kaizuka-Wase-Ki }\end{array}$ \\
\hline
\end{tabular}




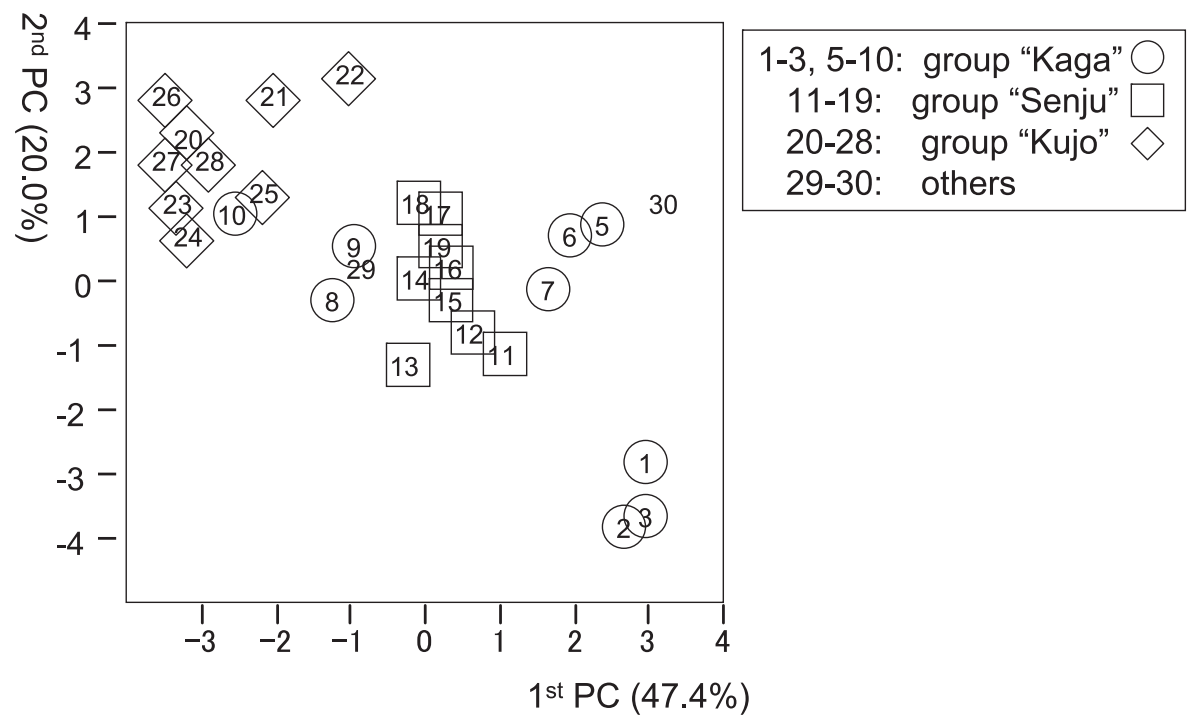

Fig. 1. Diagram of principal component analysis based on nine morphological traits (leaf blade length, leaf sheath length, flower stalk length, pedicel length, leaf blade width, leaf sheath width, flower stalk width, numbers of tillers and 1000-seed weight) of bunching onion varieties (Wako et al. 2009). Varieties belonging to groups 'Kaga', 'Senju' and 'Kujo' are represented by circles, squares and diamonds, respectively. Variety numbers correspond to those in Table 1.

\section{Genotyping and statistical analysis}

To assess the degree of DNA polymorphism at each SSR locus, we evaluated the number of alleles and the total heterozygosity $\left(\mathrm{H}_{\mathrm{T}}\right)$ for each SSR locus. The $\mathrm{H}_{\mathrm{T}}$ value was calculated according to the following formula (Anderson et al. 1993):

$$
\mathrm{H}_{\mathrm{T}}=1-\sum_{i=1}^{k} P_{i}^{2}
$$

where $k$ is the total number of alleles detected at a locus and $P_{i}$ is the frequency of the $i$ th allele in all of bunching onion individuals genotyped.

The average values for the within-variety heterogeneity $\left(\mathrm{H}_{\mathrm{S}}\right)$, the among-variety variability $\left(\mathrm{D}_{\mathrm{ST}}\right)$, and the amongvariety variability relative to the total variability $\left(\mathrm{G}_{\mathrm{ST}}\right)$ were calculated according to Nei (1973). The analysis of Molecular Variance (AMOVA) was calculated by using GenAlEx 6.2 (Peakall and Smouse 2006). For evaluation of genetic heterogeneity for each variety, the number of alleles, number of genotypes and proportion of individuals showing the prevailing genotype (the most frequent genotype within each variety, $\operatorname{Pr} \%$ ) were calculated. Genetic distance was calculated from allele frequencies of each locus according to Nei (1972), and cluster analysis based on both the Unweighted Pair Group Method using arithmetic Average (UPGMA) and the Neighbor-Joining (NJ) method was conducted using Populations 1.2.30beta (Langella 2007).

\section{Assignment test}

The likelihoods of multilocus genotype were calculated for each tested individual in each variety following Rannala and Mountain (1997). Briefly, we calculated the frequency for each allele of each variety by the Bayesian method. Then the likelihood of a diploid genotype occurring in a particular variety was estimated under the assumption of random mating within a variety. When the sample of the variety included a tested individual, the observed allele frequencies in the variety were obtained after removing the individual from the sample. We regarded the variety giving the highest likelihood as a variety that the tested individual was derived from.

A total of 1000 diploid genotypes were generated by resampling from each of the varieties to generate the empirical distribution of the likelihoods under the null hypothesis that a tested individual was derived from the variety following Paetkau et al. (2004). By comparing the observed likelihood of a tested individual with the empirical distribution in the variety, we obtained the significance level of the likelihood in the variety, which was called membership probability indicating the confidence of the tested individual to be derived from the variety. To obtain the probabilities of the tested individual to be misclassified in the wrong variety, we evaluated the relative frequency of individuals in a variety showing the membership probability of more than $5 \%$ in the assignment test to each of the varieties. The membership probabilities were calculated with GeneClass2 (Piry et al. 2004).

Because variety identification may be conducted in a lot unit in its practical application, we also computed the likelihood of each group, which consisted of randomly selected four individuals within each source variety, occurring in each reference variety. This assignment was conducted for 1000 groups per variety. The likelihood, $L$, was calculated as follows:

$$
L=\frac{m !}{m_{1} ! m_{2} ! \cdots m_{k} !} P_{1}^{m 1} P_{2}^{m 2} \cdots P_{k}^{m}
$$

where $m$ is the total number of individuals to be assigned, $m_{k}$ is the number of copies of genotype $k$ in the to-be-assigned sample, and $P_{k}$ is the frequency of genotype $k$ in the 


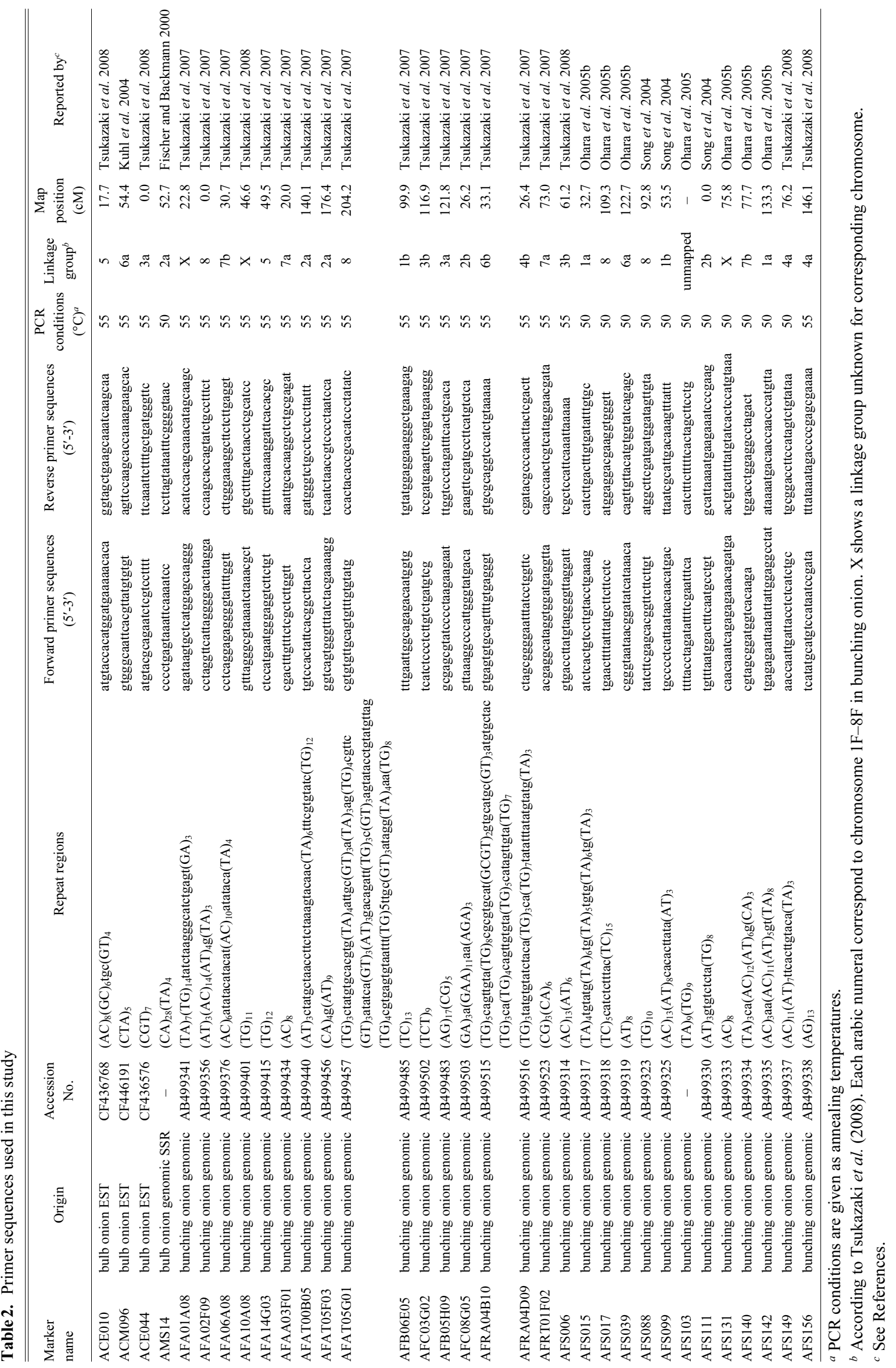


reference variety sample $\left(p_{i}{ }^{2}\right.$ for homozygotes and $2 p_{i} p_{j}$ for heterozygotes, with $p_{i}$, the frequency of allele $i$ ). In a similar way to the assignment at the individual level, we evaluated the membership probability by comparing the likelihood of a group to the distribution of likelihoods generated based on 1000 groups of each reference variety.

\section{Results}

\section{Polymorphism of SSR loci in A. fistulosum}

In $A$. altaicum or bulb onion, three SSR markers (AFAT05F03, AFS099 and AFS103) could not be amplified stably, whereas the other 30 markers could be amplified well. A. altaicum and bulb onion-specific alleles were detected at 21 and 19 loci, respectively (data not shown).

Within bunching onion, the number of alleles per locus varied from 3 to 30 with an average of 10.4, and the size difference of amplified alleles at each SSR locus ranged from 4 to $80 \mathrm{bp}$ with an average of $26.6 \mathrm{bp}$ (Table 3 ). Sequence analysis of PCR fragments verified that the differences in size of PCR fragments were due to SSR repeats (data not shown). Genomic SSRs, except for AFRT01F02 and AFS111, were more polymorphic than bulb onion ESTderived SSR markers (Table 3 ).

The total heterozygosity at 33 SSR loci in bunching onion ranged from 0.25 (ACM096) to 0.98 (AFS017) with an average of 0.71 (Table 3 ). The within-variety heterogeneity $\left(\mathrm{H}_{\mathrm{S}}\right)$, the among-variety variability $\left(\mathrm{D}_{\mathrm{ST}}\right)$, and the amongvariety variability relative to the total variability $\left(\mathrm{G}_{\mathrm{ST}}\right)$ ranged from 0.22 to 0.73 (average 0.53 ), 0.02 to 0.42 (average 0.17 ), and 0.03 to 0.47 (average 0.23 ), respectively (Table 3). The analysis of Molecular Variance (AMOVA) revealed that $77 \%$ of molecular variance was within varieties (variation among varieties was $23 \%$ ).

\section{Polymorphism within bunching onion varieties}

The mean number of alleles per locus ranged from 2.1 to 5.3 with an average of 4.1 and that of genotypes within each variety ranged from 2.8 to 8.7 with an average of 6.4 (Table 4). The average $\operatorname{Pr} \%$ of each variety ranged from 31 to 66 (Table 4). Among the 990 loci (30 varieties $\times 33$ SSR loci), only 27 loci $(2.7 \%)$ in nine varieties were considered to be genetically uniform (data not shown). However, ten of these were found in one variety ('Motoharu-Bansei', No. 29) and six in another variety ('Koshizu' No. 22).

\section{Classification of bunching onion}

Among the 30 bunching onion varieties, the genetic distances between each pair of varieties ranged from 0.04 to 0.77 with an average 0.29 . The minimum genetic distance was found between 'Tokyo-Fuyuguro-Ipponfuto' (variety No. 15) and 'Omiyakuro' (No. 16), and the maximum value was shown between 'Kiyotaki' (No.18) and 'Shokyu' (No. 30).

From a cluster analysis based on 30 SSR loci that could be amplified well in A. altaicum and A. cepa, bunching
Table 3. Polymorphism at 33 SSR loci among 30 bunching onion varieties

\begin{tabular}{|c|c|c|c|c|c|c|c|}
\hline Locus & $\begin{array}{l}\begin{array}{l}\text { Linkage } \\
\text { group }^{a}\end{array}\end{array}$ & $\begin{array}{l}\text { Size range } \\
\text { (bp) }\end{array}$ & Alleles & $\mathrm{H}_{\mathrm{T}}^{b}$ & $\mathrm{H}_{\mathrm{S}}^{c}$ & $\mathrm{D}_{\mathrm{ST}^{d}}^{d}$ & $\mathrm{G}_{\mathrm{ST}^{e}}$ \\
\hline AFS015 & $1 \mathrm{a}$ & $316-384(68)$ & 13 & 0.93 & 0.60 & 0.33 & 0.36 \\
\hline AFS142 & $1 \mathrm{a}$ & $240-253(13)$ & 8 & 0.89 & 0.50 & 0.39 & 0.44 \\
\hline AFS099 & $1 b$ & $210-263(53)$ & 19 & 0.96 & 0.68 & 0.27 & 0.29 \\
\hline AFB05H09 & $1 b$ & 266-274 (8) & 5 & 0.53 & 0.42 & 0.11 & 0.20 \\
\hline AMS14 & $2 a$ & $116-164(48)$ & 21 & 0.79 & 0.62 & 0.17 & 0.21 \\
\hline AFAT00B05 & $2 \mathrm{a}$ & $191-211(20)$ & 11 & 0.72 & 0.59 & 0.13 & 0.18 \\
\hline AFAT05F03 & $2 a$ & $213-237(24)$ & 13 & 0.82 & 0.69 & 0.13 & 0.16 \\
\hline AFS111 & $2 b$ & 229-233 (4) & 3 & 0.43 & 0.37 & 0.05 & 0.13 \\
\hline AFC08G05 & $2 b$ & $284-305(21)$ & 8 & 0.64 & 0.55 & 0.09 & 0.14 \\
\hline ACM096 & $3 a$ & $270-276(6)$ & 3 & 0.39 & 0.29 & 0.10 & 0.25 \\
\hline $\mathrm{AFC} 03 \mathrm{G} 02$ & $3 a$ & $153-177(24)$ & 8 & 0.60 & 0.49 & 0.10 & 0.17 \\
\hline AFS006 & $3 b$ & $282-308(24)$ & 13 & 0.78 & 0.62 & 0.16 & 0.21 \\
\hline AFB06E05 & $3 b$ & $127-155(28)$ & 10 & 0.75 & 0.61 & 0.14 & 0.19 \\
\hline AFS149 & $4 a$ & $191-213(22)$ & 12 & 0.74 & 0.57 & 0.17 & 0.23 \\
\hline AFS156 & $4 a$ & $208-222(14)$ & 8 & 0.66 & 0.57 & 0.09 & 0.14 \\
\hline AFRA04D09 & $4 b$ & $114-154(40)$ & 5 & 0.54 & 0.39 & 0.16 & 0.29 \\
\hline ACE010 & 5 & $165-171(6)$ & 4 & 0.49 & 0.35 & 0.13 & 0.28 \\
\hline AFA14G03 & 5 & $212-222(10)$ & 6 & 0.62 & 0.51 & 0.11 & 0.18 \\
\hline ACE044 & $6 a$ & $184-188(5)$ & 5 & 0.55 & 0.47 & 0.08 & 0.15 \\
\hline AFS039 & $6 a$ & $283-312(29)$ & 15 & 0.96 & 0.66 & 0.30 & 0.31 \\
\hline AFRA04B10 & $6 b$ & $284-300(16)$ & 7 & 0.77 & 0.57 & 0.20 & 0.26 \\
\hline AFAA03F01 & $7 \mathrm{a}$ & 230-238 (8) & 5 & 0.56 & 0.54 & 0.02 & 0.03 \\
\hline AFRT01F02 & $7 \mathrm{a}$ & 220-224 (4) & 3 & 0.47 & 0.35 & 0.12 & 0.25 \\
\hline AFA06A08 & $7 b$ & $142-198(56)$ & 13 & 0.85 & 0.64 & 0.21 & 0.25 \\
\hline AFS140 & $7 \mathrm{~b}$ & $191-246(55)$ & 18 & 0.97 & 0.66 & 0.30 & 0.31 \\
\hline AFA02F09 & 8 & $264-298$ & 11 & 0.76 & 0.57 & 0.19 & 0.25 \\
\hline AFAT05G01 & 8 & 294-314 (20) & 8 & 0.25 & 0.22 & 0.02 & 0.09 \\
\hline AFS017 & 8 & $189-269(80)$ & 19 & 0.98 & 0.68 & 0.30 & 0.30 \\
\hline AFS088 & 8 & $155-170(15)$ & 8 & 0.93 & 0.53 & 0.40 & 0.43 \\
\hline AFA01A08 & $\mathrm{X}$ & $296-322(26)$ & 14 & 0.84 & 0.73 & 0.10 & 0.12 \\
\hline AFA10A08 & $\mathrm{X}$ & 284-304 (20) & 10 & 0.41 & 0.38 & 0.04 & 0.09 \\
\hline AFS131 & $\mathrm{X}$ & $154-166$ (12) & 7 & 0.89 & 0.47 & 0.42 & 0.47 \\
\hline AFS103 & unmapped & $198-262(64)$ & 30 & 0.97 & 0.73 & 0.24 & 0.25 \\
\hline lea & & (27) & 10. & 0.71 & 0.53 & 0.17 & 0.24 \\
\hline
\end{tabular}

${ }^{a}$ According to Tsukazaki et al. (2008). Each arabic numeral corresponds to chromosome $1 \mathrm{~F}-8 \mathrm{~F}$ in bunching onion. $\mathrm{X}$ shows a linkage group unknown for corresponding chromosome.

${ }^{b}$ Total heterozygosity.

${ }^{c}$ Within-variety heterogeneity.

${ }^{d}$ Variation among varieties.

${ }^{e}$ Relative differentiation among varieties.

onion varieties were classified into three clusters. These clusters corresponded to the expected variety groups, that is, 'Kaga' (clusters A3 and B2), 'Senju' (clusters A2 and B1) and 'Kujo' (clusters A3 and B3). An exception was 'Iwatsuki-2' (No. 10), which classified as a member of the 'Kujo' group (Fig. 2). In contrast, two related species, A. altaicum and A. cepa, were located as outgroups (Fig. 2).

\section{Assignment test}

The $89.1 \%$ of individuals $(637 / 715)$ showed the highest likelihood in their original variety (Table 5). All individuals 
Table 4. Polymorphism of 30 bunching onion varieties at 33 SSR loci

\begin{tabular}{|c|c|c|c|c|c|c|c|c|c|}
\hline \multirow{2}{*}{$\begin{array}{c}\text { Variety } \\
\text { no. }{ }^{a}\end{array}$} & \multicolumn{3}{|c|}{ No. of alleles } & \multicolumn{3}{|c|}{ No. of genotypes } & \multicolumn{3}{|c|}{ 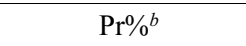 } \\
\hline & Min. & Max. & Average & Min. & Max. & Average & Min. & Max. & Average \\
\hline 1 & 1 & 7 & 3.2 & 1 & 16 & 5.2 & 13 & 100 & 44 \\
\hline 2 & 2 & 11 & 3.9 & 3 & 13 & 5.8 & 11 & 87 & 45 \\
\hline 3 & 2 & 10 & 4.1 & 2 & 18 & 6.8 & 6 & 88 & 38 \\
\hline 4 & 2 & 10 & 4.1 & 2 & 16 & 6.5 & 8 & 96 & 43 \\
\hline 5 & 2 & 10 & 4.6 & 2 & 15 & 6.9 & 8 & 83 & 38 \\
\hline 6 & 2 & 9 & 4.1 & 2 & 13 & 6.0 & 8 & 83 & 42 \\
\hline 7 & 2 & 9 & 4.1 & 3 & 14 & 6.4 & 8 & 96 & 36 \\
\hline 8 & 2 & 13 & 5.3 & 2 & 16 & 8.7 & 13 & 96 & 36 \\
\hline 9 & 2 & 8 & 4.0 & 3 & 15 & 6.8 & 9 & 83 & 39 \\
\hline 10 & 2 & 10 & 4.8 & 3 & 15 & 7.7 & 8 & 88 & 36 \\
\hline 11 & 2 & 8 & 4.6 & 2 & 15 & 7.1 & 9 & 88 & 35 \\
\hline 12 & 2 & 9 & 4.4 & 2 & 15 & 6.5 & 16 & 96 & 42 \\
\hline 13 & 2 & 11 & 4.5 & 2 & 18 & 7.2 & 4 & 96 & 39 \\
\hline 14 & 1 & 7 & 3.7 & 1 & 11 & 5.5 & 14 & 100 & 48 \\
\hline 15 & 2 & 10 & 4.7 & 2 & 14 & 7.4 & 5 & 83 & 31 \\
\hline 16 & 2 & 12 & 4.5 & 2 & 17 & 6.8 & 9 & 92 & 36 \\
\hline 17 & 2 & 10 & 4.2 & 2 & 15 & 6.1 & 17 & 96 & 42 \\
\hline 18 & 1 & 7 & 3.8 & 1 & 11 & 5.5 & 8 & 100 & 48 \\
\hline 19 & 1 & 9 & 4.4 & 1 & 15 & 7.1 & 4 & 100 & 35 \\
\hline 20 & 1 & 8 & 3.4 & 1 & 13 & 4.8 & 11 & 100 & 56 \\
\hline 21 & 1 & 11 & 3.6 & 1 & 15 & 5.4 & 13 & 100 & 45 \\
\hline 22 & 1 & 5 & 3.0 & 1 & 11 & 4.6 & 13 & 100 & 53 \\
\hline 23 & 2 & 7 & 3.9 & 2 & 15 & 6.4 & 8 & 86 & 38 \\
\hline 24 & 2 & 8 & 5.0 & 3 & 15 & 7.6 & 13 & 75 & 37 \\
\hline 25 & 2 & 10 & 5.1 & 3 & 14 & 7.7 & 9 & 71 & 33 \\
\hline 26 & 2 & 11 & 4.5 & 2 & 16 & 7.5 & 4 & 75 & 32 \\
\hline 27 & 2 & 8 & 4.2 & 2 & 15 & 6.8 & 8 & 75 & 36 \\
\hline 28 & 2 & 7 & 3.9 & 2 & 13 & 6.4 & 11 & 88 & 36 \\
\hline 29 & 1 & 5 & 2.1 & 1 & 8 & 2.8 & 13 & 100 & 66 \\
\hline 30 & 1 & 9 & 3.8 & 1 & 16 & 5.8 & 9 & 100 & 46 \\
\hline Mean & & & 4.1 & & & 6.4 & & & 41 \\
\hline
\end{tabular}

${ }^{a}$ Corresponding to Table 1 .

${ }^{b}$ Calculated as follows:

$\operatorname{Pr} \%=($ No. of plants with prevailing genotype $) /($ No. of plants genotyped) $\times 100$.

of five varieties ('Choho', 'Nishida', 'Koshizu-Nebuka', 'Motoharu-Bansei' and 'Shokyu') showed the highest likelihood in their original variety. Most of the varieties showed a high degree of correct assignment (over 80\%), except for five varieties: 'Kujofuto-2' (50.0\%), 'Omiyakuro' (60.9\%), 'Kujofuto-1' (66.7\%), 'Tokyo-Fuyuguro-Ipponfuto' (70.8\%) and 'Yoshikura' (79.2\%). In 'Omiyakuro', five of 23 individuals were misassigned to 'Yoshikura'. Four of 24 individuals in 'Yoshikura' were also misassigned to 'Omiyakuro'. The genetic distance between these varieties was considerably low, at 0.05 . Similar results were found in combinations with 'Tokyo-Fuyuguro-Ipponfuto' and 'Kanehiko', and 'Kujofuto-2' and 'Wakamidori', whose genetic distances were 0.04 and 0.06 , respectively. In Table 6 , we showed the proportion of individuals which showed the membership probability more than 0.05 in each reference variety. Most of individuals of the source varieties except for 'Shokyu' showed the membership probability more than 0.05 in multiple reference varieties. For example, more than $90 \%$ of individuals of 'Choho' showed the membership probability more than 0.05 in 'Yoshikura', 'Kachinanori', 'Tokyo-Fuyuguro-Ipponfuto' and 'Omiyakuro' as well as in itself. In contrast, 'Shokyu' showed the probability above 0.05 only in itself. As a result, the total number of varieties which was not excluded as the possible origin, ranged from one of 'Shokyu' to 17 of 'Raitei-Shimonita' and 'Miyanegi'.

When the assignment was conducted based on the group unit, the percentage of correct assignment was considerably improved (99.3\%; Table 7). All groups of 23 varieties showed the highest likelihood in their original variety. Even though the percentage of correct assignment of 'Kujofuto-2' was $50.0 \%$ at the individual level, the value reached $93.9 \%$. We showed the proportion of groups which showed the membership probability more than 0.05 in each reference variety in Table 8 . The most prominent change was the membership probability of 'Asagikei-Kujo-2' to 'Kujofuto1'; despite all individuals of 'Asagikei-Kujo-2' showed the probability more than 0.05 in 'Kujofuto-1' at the individual level, no groups showed the values above 0.05 . As a result, the total number of varieties which was not excluded as the possible origin, generally decreased as compared to the assignment at the individual level. In the four varieties ('Iwatsuki-1', 'Kiyotaki', 'Motoharu-Bansei', 'Shokyu'), all groups showed the probability above 0.05 only in themselves.

\section{Discussion}

In the present study, we investigated DNA polymorphisms within and/or among bunching onion varieties based on SSR markers and attempted variety classification based on allele frequencies at each locus. Within 30 bunching onion varieties, the number of alleles per locus at each SSR loci ranges from 3 to 30 with an average 10.4 (Table 3). Compared with the polymorphisms at SSR loci reported in maize accessions and inbred lines (alleles per locus range from 2 to 13 with an average of 6.5, Labate et al. 2003) and in our previous study using bunching onion $F_{1}$ varieties (alleles per locus range from 2 to 7 with an average of 3.1, Tsukazaki et al. 2006), these results show that bunching onion varieties have a very high degree of genetic diversity. The average value of within-variety heterogeneity $\left(\mathrm{H}_{\mathrm{S}}, 0.53\right)$ was much higher than that of the among-variety variability $\left(\mathrm{D}_{\mathrm{ST}}, 0.17\right)$ in the present study (Table 3). Estimates for within-population variation obtained with SSR markers are almost three times as high as the values with dominant (RAPD, AFLP) markers. Because of the high variability of SSRs, the values for within-population variation are often much higher than that for among-population variation (reviewed in Nybom 2004).

All varieties had a high degree of heterozygosity 


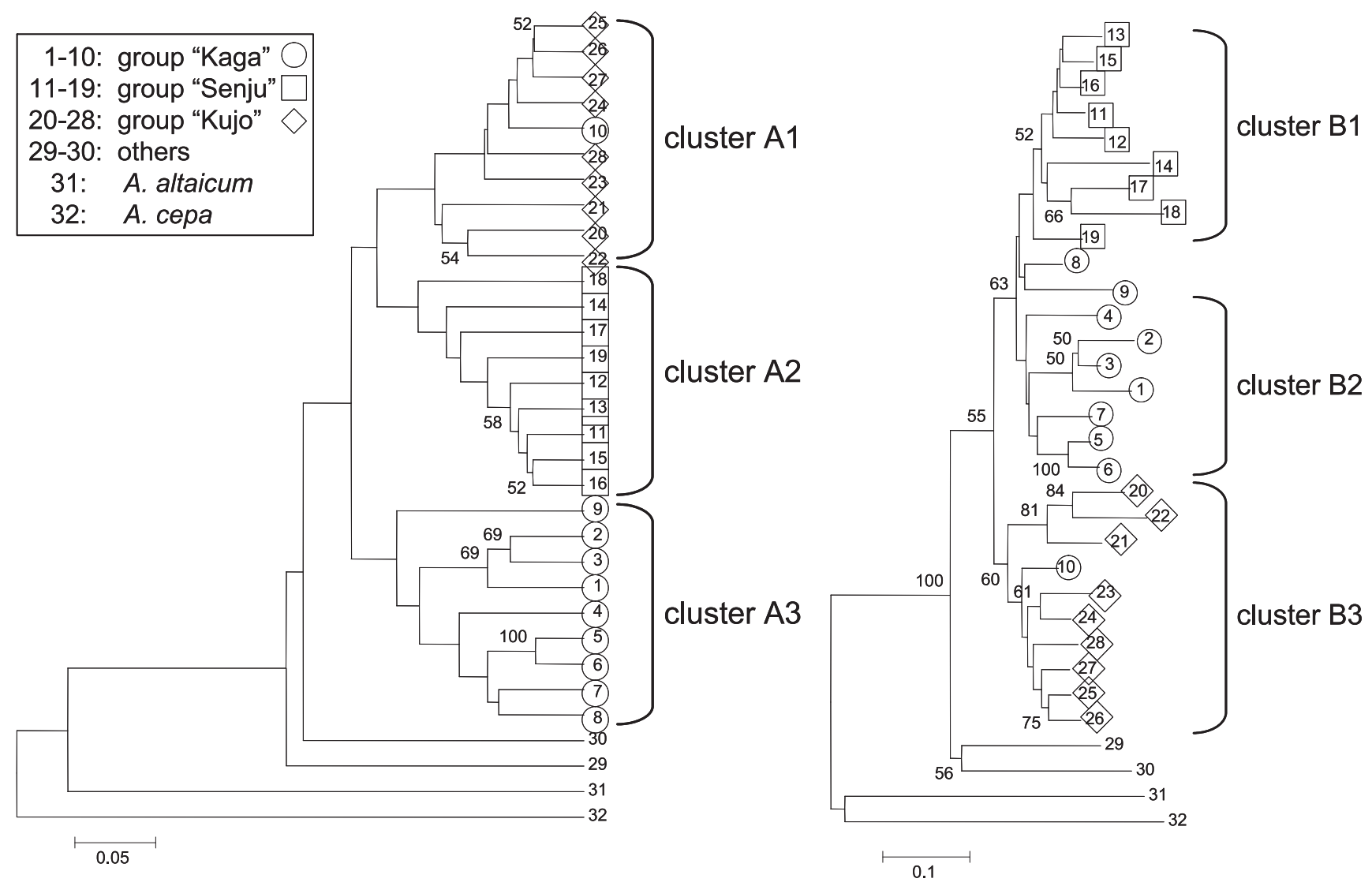

Fig. 2. Dendrogram of 30 bunching onion varieties and two related species generated by UPGMA (left) and NJ (right) cluster analysis of genetic distance based on 30 SSR loci. Varieties belonging to groups 'Kaga', 'Senju' and 'Kujo' are represented by circles, squares and diamonds, respectively. Variety numbers corresponds to those in Table 1 . Bootstrap values were shown when these were above $50 \%$.

(Table 4). However, the morphological and ecological traits are highly uniform within each variety (data not shown). Bunching onion is usually propagated by open-pollination. Therefore, this high heterogeneity at SSR loci within varieties might be held through the generations. On the other hand, nine varieties were estimated as highly uniform at between one and 10 loci (data not shown). One reason for this may be that these highly uniform SSR loci might not be tightly linked to QTLs, but may still influence growth or reproductive traits, such as flowering time or seed productivity, and expected or unexpected genetic selection for these markers may have occurred during breeding or seed production. The fixation of alleles can be also caused by random genetic drift especially when population size is small. The relationship between the SSR loci and these traits will be revealed with the accumulation of data from genomic studies in the future.

Cluster analysis was effective for variety classification (Fig. 3). The classification of bunching onion varieties was in accordance with the traditional classification based on morphological traits, for example, group 'Kaga' (Wako et al. 2009, Fig. 1). Similar results were obtained for variety classification based on molecular markers in bunching onion using isozymes (Haishima et al. 1993) and AFLPs (Ohara et al. 2005b). In contrast, our classification based on SSR markers will have the advantage because the SSRs are higher polymorphisms and more discriminative due to codominant inheritance than these markers. The simple nucleotide polymorphism (SNP) and insertion-deletion (InDel) markers are also informative markers. However, in bulb onion, the phylogenic analysis of SSRs was consistent with known pedigrees and previous marker evaluation, although SNPs and Indels did not reveal clear relationships among populations (Jakše et al. 2005). 'Iwatsuki-2' (variety No. 10) was categorized as a member of the 'Kujo' group based on cluster analysis using both UPGMA and NJ methods (Fig. 2). This variety is also located near the 'Kujo' varieties using PCA data based on nine morphological traits in our previous study (Wako et al. 2009, Fig. 1). These data indicate that 'Iwatsuki-2' might not belong to 'Kaga', and therefore, should be excluded from standard varieties of the 'Kaga' group as previously defined (Wako et al. 2009). As a landrace, 'Iwatsuki' is traditionally classified as belonging to the 'Kaga' group due to its dormancy in the winter season (Kumazawa and Katsumata 1965, Aoba 1987). However, Iwasaki (2007) reported that four 'Iwatsuki' varieties could be divided into three groups by a cultivation test, and one of these was considerably similar to a 'Kujo' variety. In addition, several 'Iwatsuki' varieties could not be explicitly distinguished from 'Kujo' varieties from PCA data based on either morphological traits or growth habits (Wako et al. 


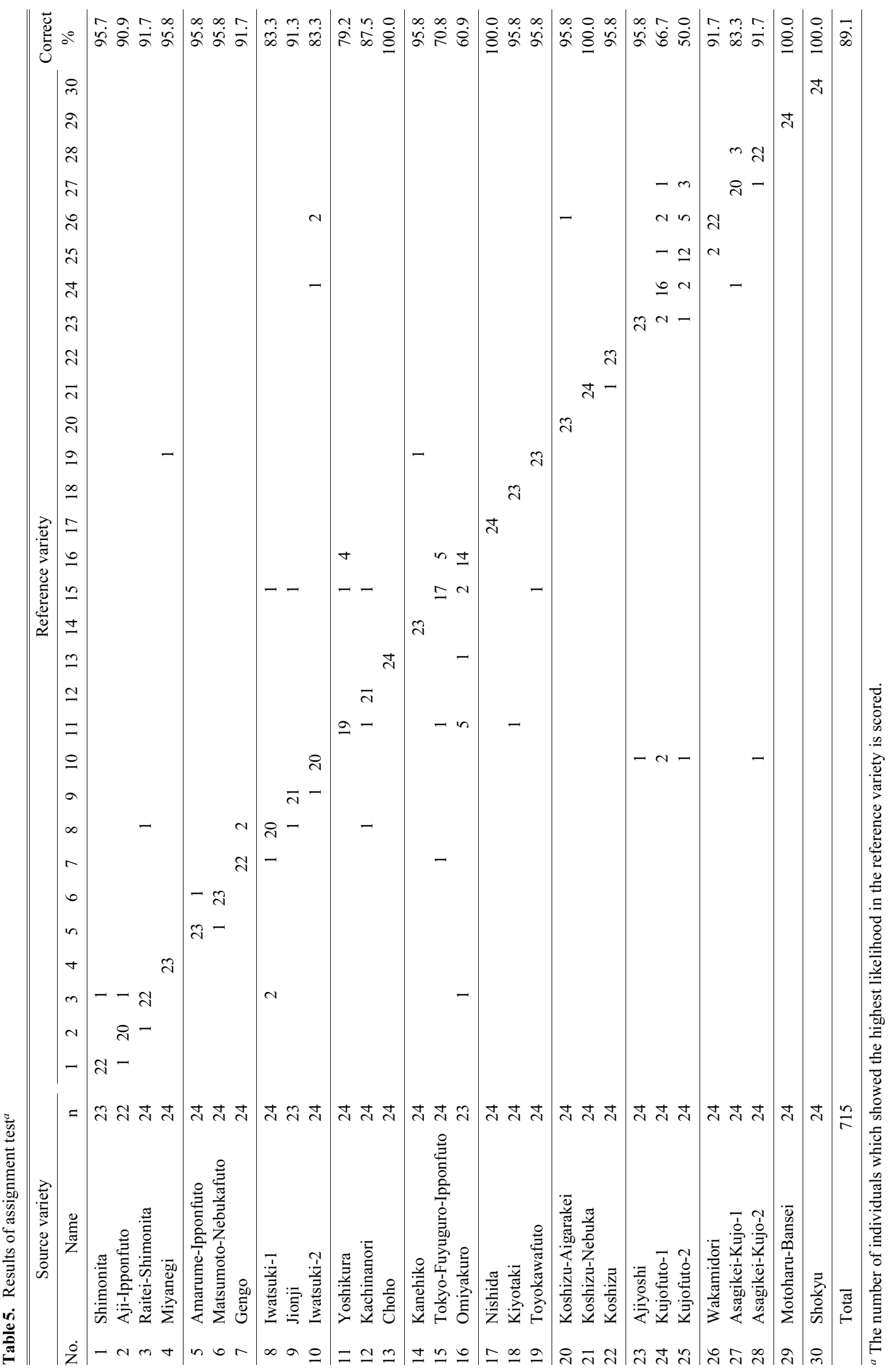




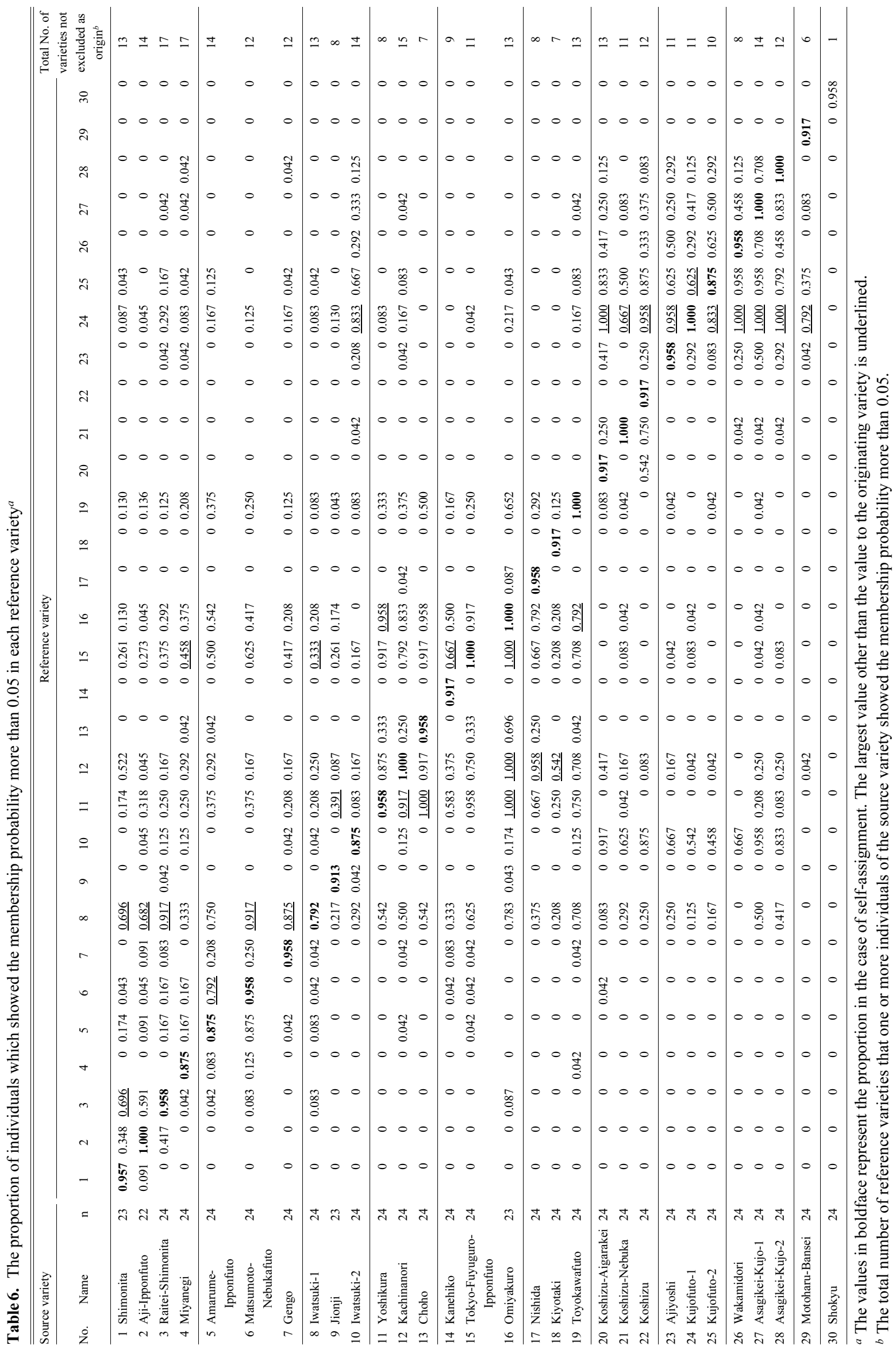




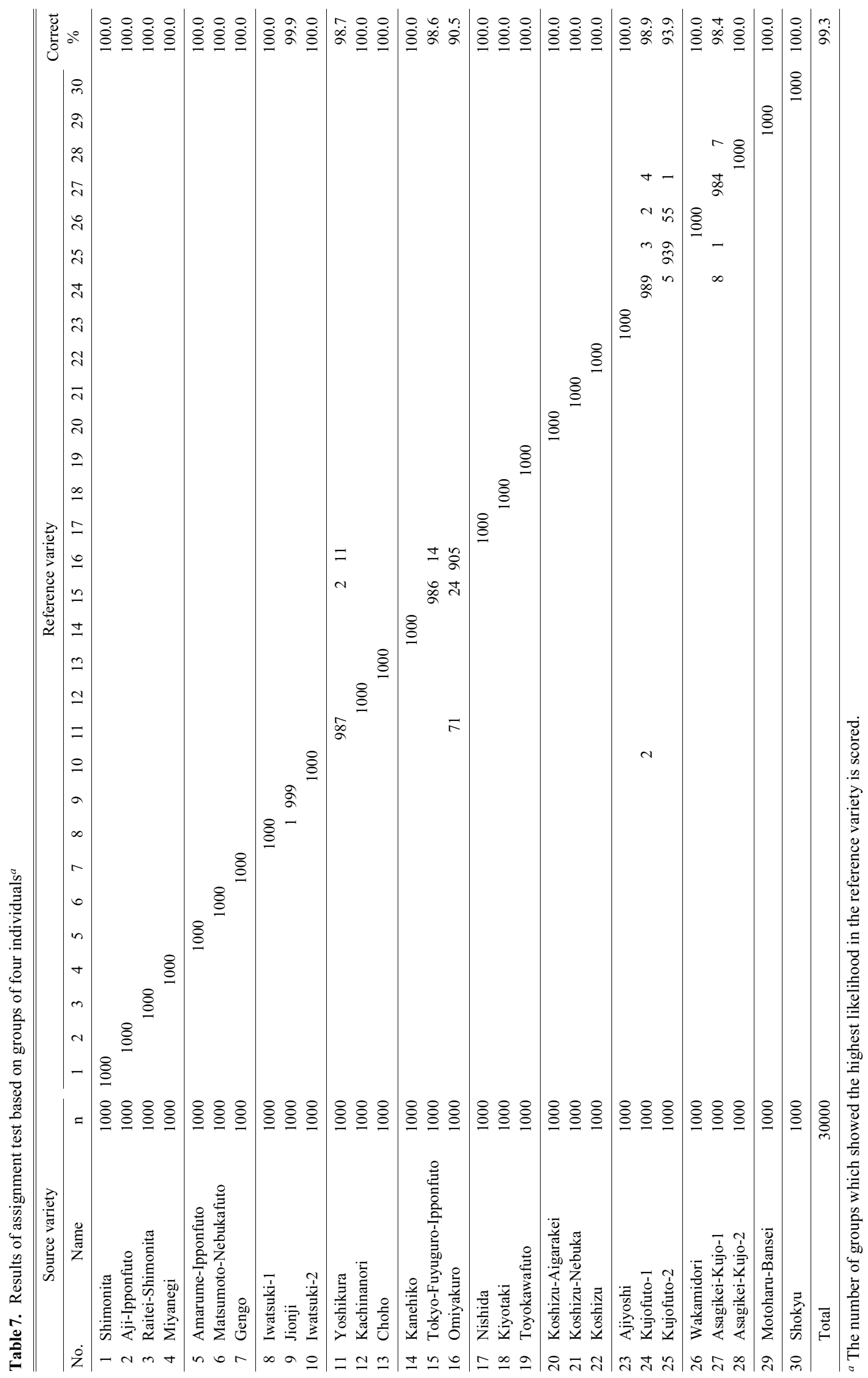




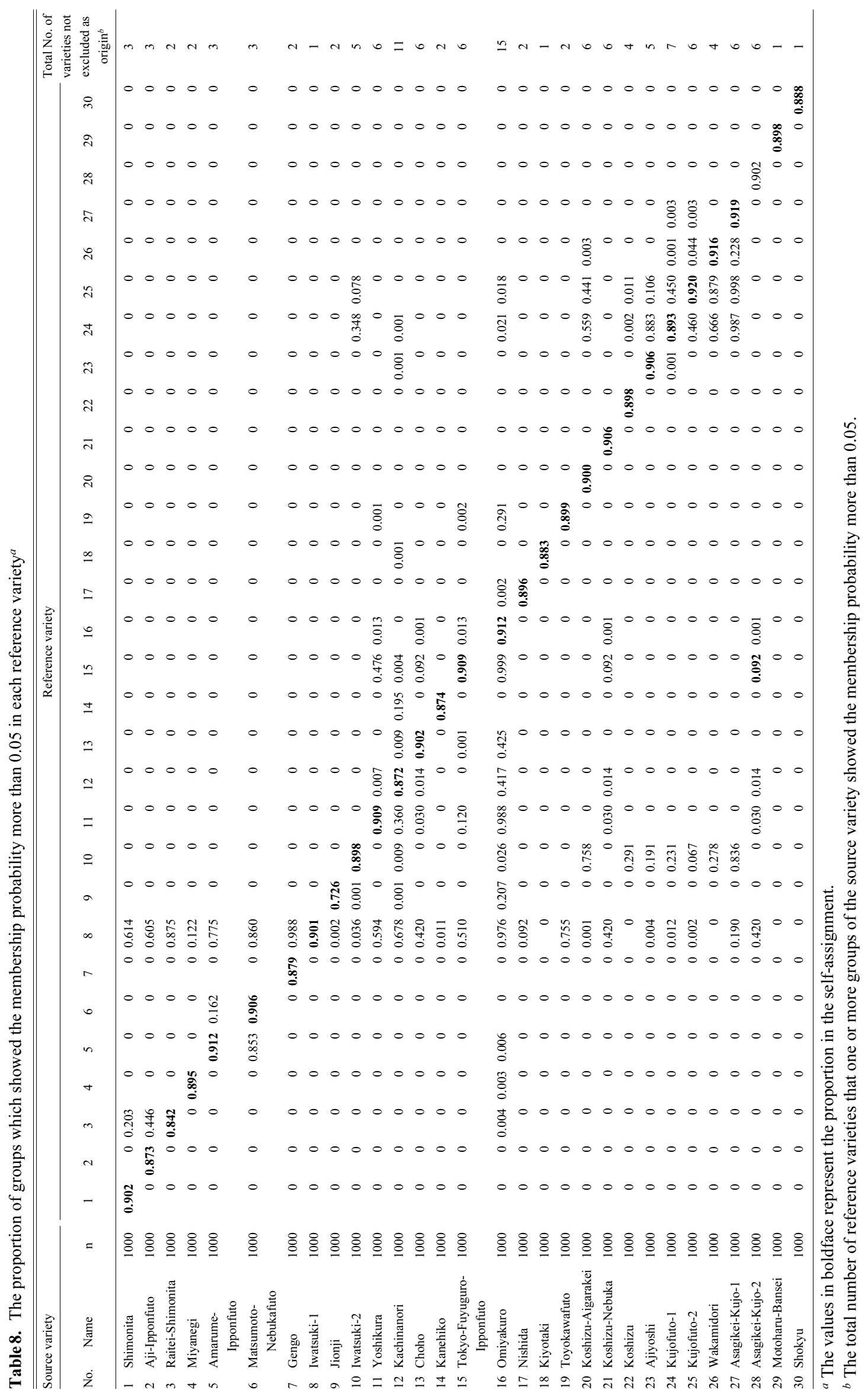


2009). Clarification of the classification of 'Iwatsuki' varieties will require further investigations into their genetic backgrounds. On the other hand, two related species, A. altaicum and $A$. серa, were distinctly different from all of the bunching onion varieties since these species have specific alleles at 21 and 19 loci, respectively (data not shown). It was reported that $A$. fistulosum formed subclusters with A. altaicum whereas it was distinct from $A$. cepa based on both RFLPs of mt and cpDNAs (Yamashita et al. 2001).

In bulb onion, several studies of variety classification based on RAPD markers have been reported (Wilkie et al. 1993, Le Thierry D'ennequin et al. 1997, Tanikawa et al. 2002). Tanikawa et al. (2002) reported 22 varieties that were categorized into six groups by cluster analysis. Le Thierry D'ennequin et al. (1997) also reported that the seedpropagated shallot is more closely related to bulb onion than to vegetatively propagated shallot. However, the chromosomal locations of the RAPD markers used in these studies have not been determined, and the relationship between clusters and various agronomic traits was also unclear. Despite the fact that some SSR-specific primers do not amplify in closely related species, SSR loci are highly preserved within species or genus. Hence, SSR markers will be a powerful tool for the classification of Allium species. In the present study, we evenly selected SSR markers from each linkage group of our bunching onion map (Tsukazaki et al. 2008), thus, our variety classification based on these anchor markers is considered to reflect genetic background of bunching onion. However, as Virk et al. (2000) pointed out, it is noticed that misleading information on genetic relationships could be obtained if anchor markers were selected from a linkage map of the population between closely related genotypes. Thus, it might be more appropriate to use unmapped markers for variety classification especially in crops that their genetics remain relatively unstudied using molecular-based approaches.

In the assignment test at the individual level (Table 5), the percentage of correct assignments was $89.1 \%$, which is lower than that in an allogamous crop, perennial ryegrass (100\%; Kubik et al. 2001) and that in a partially allogamous rape (99\%; Tommasini et al. 2003). This relatively low value of bunching onion was mainly due to the high level of misassignment in several particular varieties. The percentages of correct assignments were $50.0 \%, 60.9 \%$ and $66.7 \%$ in 'Kujofuto-2', 'Omiyakuro' and 'Kujofuto-1', respectively, while most other varieties showed a relatively high percentage of correct assignment (i.e., greater than 90\%). Varieties with low correctness were genetically similar to several other varieties, as shown in the cluster analysis (Fig. 2). The calculation of membership probability indicated that most of individuals except for those of 'Shokyu' had several other varieties which were not excluded as the origin (Table 6). For example, although all individuals of 'Choho' showed the highest likelihood in itself (Table 5), the probabilities of membership were also above 0.05 in several other varieties such as 'Yoshikura', 'Kachinanori', 'Tokyo-Fuyuguro-
Ipponfuto' and 'Omiyakuro' as well as in itself. This indicates that individuals of 'Choho' could be judged as other varieties such as above mentioned, if true source variety (that is 'Choho') is not included in a reference dataset. However, the assignment test at the group level improved the accuracy of the assignment. The percentage of correct assignment was considerably improved (99.3\%; Table 7) and the total number of varieties which was not excluded as the origin decreased as compared to that at the individual level (Table 8). These results suggest that an assignment test, especially based on a group level, will be effective for variety identification in the allogamous bunching onions, which contain large amount of genetic variation within a variety. However, even in the assignment test at the group level, only four varieties ('Iwatsuki-1', 'Kiyotaki', 'Motoharu-Bansei' and 'Shokyu') were perfectly excluded from other varieties (Table 8). This suggests that sampling of true source varieties will be fundamental in variety identification in bunching onion to avoid misjudgment.

In the previous study, we proposed an "SSR-tagged breeding" scheme to enhance the efficiency, ease and accuracy of variety identification and $\mathrm{F}_{1}$ purity testing (Tsukazaki et al. 2006), and demonstrated the feasibility of this scheme by using a bunching onion landrace (Tsukazaki et al. 2009). This scheme is especially effective for $F_{1}$ purity test with investigating the degree of uniformity of designed heterozygosity at selected SSR loci. However, it is necessary for selecting plants homozygous at several SSR loci in the foundation seed field in advance. We selected 26 double and 40 quadruple homozygotes selected from preselected individuals (108 and 147, respectively) by stand observation at stock field (Tsukazaki et al. 2009). Thus, the SSR-tagged breeding scheme, even with a very small number of markers, is efficient for the identification of newly bred varieties, and consequently for $F_{1}$ purity tests, in allogamous crops. In contrast, high degree of the correct assignment rate was obtained by assignment test based on groups of individuals. The assignment test approach will be useful for variety identification not only in bunching onion but also any allogamous crops. This will be also applicable for $F_{1}$ varieties. In addition, assignment tests combined with exclusion methods can have an important role especially in conservation of landraces or genetic resources. Therefore, the scheme for variety identification in allogamous crops should be selected by the purpose and situations.

\section{Acknowledgements}

We are grateful to Ms. Misses K. Tanaka, S. Negoro and N. Kitamoto for technical assistance. This work was supported by the grant from the Ministry of Agriculture, Forestry and Fisheries of Japan (Integrated Research Program for Functionality and Safety of Food toward an Establishment of Healthy Diet (I-206), and Utilizing Advanced Technology in Agriculture, Forestry and Fisheries (1655)). 


\section{Literature Cited}

Anderson,J.A., G.A.Churchill, J.E.Autrique, S.D.Tanksley and M.E. Sorrells (1993) Optimizing parental selection for genetic linkage maps. Genome 36: 181-186.

Aoba,T. (1987) Negi (Japanese bunching onion). In: "Yasai shuruihinsyu meikou (Vegetable crops and varieties)" Nishi,S. (ed.) Nougyo Gijutsu Kyokai, Tokyo, pp. 362-378.

Fischer,D. and K.Bachmann (2000) Onion microsatellites for germplasm analysis and their use in assessing intra- and interspecific relatedness within the subgenus Rhizirideum. Theor. Appl. Genet. 101: 153-164.

Ford-Lloyd, B.V. and S.J.Armstrong (1993) Welsh onion Allium fistulosum L. In: "Genetic Improvement of Vegetable Crops" Kalloo,G. and B.O.Bergh (eds.) Pergamon Press, London, pp. 5158.

Friesen, N., S.Pollner, K.Bachmann and F.R.Blattner (1999) RAPDs and non-coding chloroplast DNA reveal a single origin of the cultivated Allium fistulosum from A. altaicum (Alliaceae). Am. J. of Bot. 86: 554-562.

Haishima,M., J.Kato and H.Ikehashi (1993) Isozyme polymorphism in native varieties of Japanese bunching onion (Allium fistulosum L.). Jpn. J. Breed. 43: 537-547.

Inden, H. and T.Asahira (1990) Japanese bunching onion (Allium fistulosum L.). In: "Onions and Allied Crops. Volume III. Biochemistry, Food Science, and Minor Crops", Brewster,J.L and H.D.Rabinowitch (eds.) CRC press, Florida, pp. 159-178.

Iwasaki,Y. (2007) Variety test of bunching onion 'Iwatsuki'. Research Report of Agriculture and Forestry Research Center in Saitama Pref., pp. 12-14.

Jakše,J., W.Martin, J.McCallum and M.J.Havey (2005) Single nucleotide polymorphisms, indels, and simple sequence repeats for onion cultivar identification. J. Amer. Soc. Hort. Sci. 130: 912-917.

Kubik,C., M.Sawkins, W.A.Meyer and B.S.Gaut (2001) Genetic diversity in seven perennial Ryegrass (Lolium perenne L.) cultivars based on SSR markers. Crop Sci. 41: 1565-1572.

Kuhl,J.C., F.Cheung, Q.Yuan, W.Martin, Y.Zewdie, J.MaCallum, A.Catanach, P.Rutherford, K.C.Sink, M.Jenderk et al. (2004) A unique set of 11,008 onion expressed sequence tags reveals expressed sequence and genomic differences between the monocot orders Asparagales and Poales. Plant Cell 16: 114-125.

Kumazawa,S. and H.Katsumata (1965) Negi (Japanese bunching onion). In: "Sosai-engei kakuron (Vegetable crops)" Kumazawa, S. (ed.) Yokendo Press, Tokyo, pp. 280-289.

Labate,J.A., K.R.Lamkey, S.E.Mitchell, S.Kresovich, H.Sullivan and J.S.C.Smith (2003) Molecular and historical aspects of Corn Belt dent diversity. Crop Sci. 43: 80-91.

Langella,O. (2007) Populations 1.2.30: Population genetic software (individuals or population distances, phylogenetic trees.) http:// bioinformatics.org/ tryphon/populations/

Le Thierry, D'ennequin,M., O.Panaud, T.Robert and A.Richroch (1997) Assessment of genetic relationships among sexual and asexual forms of Allium cepa using morphological traits abd RAPD markers. Heredity 78: 403-409.

MAFF (2008) Nousanbutsu-Sanshutsugaku no Jun-I (The ranking of vegetables for annual output in Japan). In "Seisan nougyou shotoku toukei (2006)". http://www.e-stat.go.jp/SG1/estat/List.do?lid= 000001031687B2004-002-004-002.

Manel,S., O.E.Gaggiotti and R.S.Waples (2005) Assignment methods: matching biological questions with appropriate techniques. Trends in Ecol. Evol. 20: 136-142.
Martin,W.J., J.McCallum, M.Shigyo, J.Jakše, J.C.Kuhl, N.Yamane, M.Pither-Joyce, A.F.Gökçe, K.C.Sink, C.D.Town and M.J.Havey (2005) Genetic mapping of expressed sequences in onion and in silico comparisons with rice show scant colinearity. Mol. Gen. Genomics 274: 197-204.

Nei,M. (1972) Genetic distance between populations. Amre. Naturalist 106: 283-292.

Nei,M. (1973) Analysis of gene diversity in subdivided populations. Proc. Natl. Acad. Sci. USA 70: 3321-3323.

Nybom,H. (2004) Comparison of different nuclear DNA markers for estimating intraspecific genetic diversity in plants. Mol. Ecol. 13: $1143-1155$.

Ohara,T., T.Wako and A.Kojima (2004) Diallel analysis of seedling growth in Japanese bunching onion (Allium fistulosum L.). Breed. Res. 6: 11-19.

Ohara,T., T.Wako, T.Nunome and A.Kojima (2005a) Heterosis for seedling growth in intervarietal $\mathrm{F}_{1}$ hybrids of Japanese bunching onion (Allium fistulosum) and its relationship to genetic distance as revealed by AFLP markers. J. Jpn. Soc. Hort. Sci. 74: 68-77.

Ohara,T., Y.S.Song, H.Tsukazaki, T. Wako, T.Nunome and A.Kojima (2005b) Genetic mapping of AFLP markers in Japanese bunching onion (Allium fistulosum). Euphytica 144: 255-263.

Peakall,R. and P.E.Smouse (2006) GENALEX 6: genetic analysis in Excel. Population genetic software for teaching and research. Mol. Ecol. Notes 6: 288-295.

Paetkau,D., R.Slade, M.Burden and A.Estoup (2004) Genetic assignment methods for the direct, real-time estimation of migration rate: a simulation based exploration of accuracy and power. Mol. Ecol. 13: 55-65.

Piry, S., A. Alapetite, J.M. Cornuet, D. Paetkau, L. Baudouin and A.Estoup (2004) GENECLASS2: A software for genetic assignment and first-generation migrant detection. J. Hered. 95: 536-539.

Rannala,B. and J.L.Mountain (1997) Detecting immigration by using multilocus genotypes. Proc. Natl. Acad. Sci. USA 94: 9197-9221.

Song, Y.S., K.Suwabe, T.Wako, T.Ohara, T.Nunome and A.Kojima (2004) Development of microsatellite markers in Japanese bunching onion (Allium fistulosum L.). Breed. Sci. 54: 361-365.

Tanikawa,T., M.Takagi and M.Ichii (2002) Cultivar identification and genetic diversity in onion (Allium cepa $\mathrm{L}$.) as evaluated by random amplified polymorphic DNA (RAPD) analysis. J. Jpn. Soc. Hort. Sci. 71: 249-251.

Tommasini,L., J.Batley, G.Arnold, R.Cooke, P.Donini, D.Lee, J.Law, C.Lowe, C.Moule, M.Trick et al. (2003) The development of multiplex simple sequence repeat (SSR) markers to complement distinctness, uniformity and stability testing of rape (Brassica napus L.) varieties. Theor. Appl. Genet. 106: 1091-1101.

Tsukazaki,H., H.Fukuoka, Y.S.Song, K. Yamashita, T.Wako and A.Kojima (2006) Considerable heterogeneity in commercial $F_{1}$ varieties of bunching onion (Allium fistulosum) and the proposal of a breeding scheme for conferring genetic traceability using SSR markers. Breed. Sci. 56: 321-326.

Tsukazaki, H., T.Nunome, H.Fukuoka, H.Kanamori, I.Kono, K. Yamashita, T.Wako and A.Kojima (2007) Isolation of 1,796 SSR clones from SSR-enriched DNA libraries of bunching onion (Allium fistulosum). Euphytica 157: 83-94.

Tsukazaki,H., K. Yamashita, S. Yaguchi, S. Masuzaki, H.Fukuoka, J.Yonemaru, H.Kanamori, I.Kono, T.T.H.Hang, M.Shigyo et al. (2008) Construction of SSR-based chromosome map in bunching onion (Allium fistulosum). Theor. Appl. Genet. 117: 1213-1223.

Tsukazaki,H., K.Yamashita, A.Kojima and T.Wako (2009) SSRtagged breeding scheme for allogamous crops: a trial in bunching 
onion (Allium fistulosum). Euphytica 169: 327-334.

Virk,P.S, H.J.Newbury, M.T.Jackson and B.V.Ford-Lloyd (2000) Are mapped markers more useful for assessing genetic diversity? Theor. Appl. Genet. 100: 607-613.

Wako,T., T.Ohara, Y.S.Song and A.Kojima (2002) Development of SSR markers in bunching onion. Breed. Res. 4 (Suppl. 1): 83.

Wako,T., H.Tsukazaki, T.Ohara, M.Yoshida, S.Shimazaki, T.Ando, K. Yamashita and A.Kojima (2009) Verification of variety classification of bunching onion based on principal component analysis of morphological traits and growth habit. Bull. Nati. Inst. Veg. \& Tea
Sci. 8: 121-130.

Wilkie, S.E., P.G.Issac and R.J.Slater (1993) Random amplified polymorphic DNA (RAPD) markers for genetic analysis in Allium. Theor. Appl. Genet. 86: 497-504.

Yamashita, K., T. Oyama， R. Noda， T. Miyazaki， S. Isshiki and Y.Tashiro (2001) Phylogenetic relationships among cultivated and wild species in section Cepa of Allium based on RFLPs of mitochondrial and chloroplast DNAs. J. Jpn. Soc. Hort. Sci. 70: 195-201. 